\title{
Studies on Lignin
}

\section{Part V. A Reexamination of Hydrogen Sulfide Cooking of Vanillyl Alcohol, and Conversion of Vanillyl Disulfide into Vanillyl Monosulfide}

Sir :

In the course of studies conducted on the reaction of lignin in the sulfate process, Enkvist and Moilanen found that vanillyl alcohol, which had already been known as an important lignin model compound in the sulfite process, would form vanillyl disulfide upon cooking with a hydrogen sulfide solution.(1) Later, contrary to this finding, Mikawa obtained a mixture of vanillyl monosulfide and vanillyl disulfide from the result of a similar experiment.(2) Mikawa, to account for this discrepancy, has discussed the amount of oxygen in ampoule, and Enkvist, in his personal letter to Mikawa, has pointed out the difference of $\mathrm{pH}$ in cooking solutions and the concentration of hydrogen sulfide. (2)

In an attempt to find out the factors which determine the formation of vanillyl disulfide or vanillyl monosulfide, a series of experiments on the hydrogen sulfide cooking of vanillyl alcohol at various $\mathrm{pH}$ was carried out. Result of cookings $\left(100^{\circ}, 7\right.$ hours $)$ in acetate buffer solutions is shown in Table I. On the

TABLE I
Cooking solution

$\begin{array}{cccc}\mathrm{Na}_{2} \mathrm{~S} \cdot 9 \mathrm{H}_{2} \mathrm{O} 1.7 \mathrm{~g} & \mathrm{AcOH} & 0.6 \mathrm{cc} / 50 \mathrm{cc} \\ \prime \prime & + & \prime \prime & 0.5 \\ \prime \prime & + & \prime \prime & 0.8 \\ \prime \prime & + & \prime \prime & 1.0\end{array}$

basis of these data, it seemed reasonable to assume that the determining factor is the $\mathrm{pH}$ of the cooking solution. Although the oxygen contents of the cooking solutions were not

1) T. Enkvist and M. Moilanen, Svensk Papperstidn.,52,183(1949).
2) H. Mikawa, Bull. Chem. Soc. Japan, 27, 50 (1954). vanillyl disulfide even after the expulsion of oxygen by bubbling through hydrogen sulfide. The reaction products, after one recrystallization from toluene, showed the same melting points as vanillyl disulfide or vanillyl monosulfide, and were identified by mixed melting point determinations with authentic specimens. However, in case of cooking with phosphate buffer solutions in which hydrogen sulfide was bubbled through, the effect of $\mathrm{pH}$ was not so distinct as in the case of acetate buffer; the main product was vanillyl monosulfide even in acidic solutions. Gierer reported that $p$-hydroxybenzyl alcohols yielded monosulfides when cooked with a sodium hydrosulfide solution of $\mathrm{pH} \mathrm{9,} \mathrm{but} \mathrm{unfortu-}$ nately no description was given on the conditions by which disulfide was formed.(3) Some unknown factors on the reaction mechanism of disulfide- and monosulfide-formation may still exist.

According to Schöberl, disulfide groups were converted into mercaptans and sulfenic acids, of which the latter were further decomposed to carbonyl groups upon heating with alkaline solution. (4) Enkvist and Moilanen Product

M.S.

M. S.

D. S.

D. S. supported this finding after they had obtained vanillin by alkali treatment of vanillyl disulfide. ${ }^{(1)}$ determined, solutions slightly acidic gave Also, on the other hand according to Schöberl, cystine (disulfide) in wool upon soda treatment is reported to yield lanthionine (monosulfide).(5) It therefore, 3) J. Gierer and B. Alfredsson, Acta Cbem. Scand, 11, 1516

4) A. Schöberl and H. Eck, Ann., 522, 97 (1936).

5) A. Schöberl, Chem. Ber., 76, 970 (1943). 
seems to be of interest to investigate the possibility of conversion of vanillyl disulfide into monosulfide, in view of the fact that while the hydrogen sulfide lignin obtained from hydrogen sulfide cooking of wood at neutral $\mathrm{pH}$, contained disulfide- and monosulfide-sulfur only monosulfide-sulfur was found in thiolignin obtained from sodium hydrosulfide cooking treatment.(6) Cooking of vanillyl disulfide with a hydrogen sulfide solution of $\mathrm{pH} 9$ has been found to yield vanillyl monosulfide. Whereas, on the other hand, vanillyl disulfide was recovered in an unchanged state by cooking with buffer solutions of the same $\mathrm{pH}$ containing no hydrogen sulfide. However, when the $\mathrm{pH}$ of borate buffer was increased to 10 or 11 , vanillyl disulfide was converted into monosulfide also being accompanied by the formation of vanillin. Based on these findings the following scheme might be proposed tentatively as :

$2 \mathrm{R}-\mathrm{CH}_{2} \mathrm{SSCH}_{2}-\mathrm{R}+2 \mathrm{H}_{2} \mathrm{O} \longrightarrow$ $\mathrm{R}-\mathrm{CH}_{2} \mathrm{SCH}_{2}-\mathrm{R}+2 \mathrm{R}-\mathrm{CHO}+3 \mathrm{H}_{2} \mathrm{~S}$ ( $R=4$-hydroxy-3-methoxyphenyl)
The determination of the reaction product however, revealed that the amount of vanilli and hydrogen sulfide thus formed is abor one half of the calculated value. Further, th amount of vanillyl monosulfide (tatal weigl of insoluble material, of which one recrysta lization from toluene yielded almost pus monosulfide) was slightly larger than expectec after cooking for seven hours at $100^{\circ}$, th over all recovery of aromatic nucleus bein about eightly per cent.

As intermediate products resulting from th process of cystine to lanthionine, Schöber presented dehydroalanine ( $\alpha$-aminoacryli acid), cysteine and serine.(7) (8) In our cas these products correspond to quinone methide vanillyl mercaptan and vanillyl alcohol, re spectively.

\section{Tatsuo IsHihara}

Tamio Kondo

Government Forest Experiment Station, Tokyo

Received April 3, 1958

(7) A. Schöberl and A. Wagner, Angew. Chem., 68, 215 (1956)

(8) of H. Musso, ibid., 68, 313 (1956).

(6) T. Enkvist and E. Hägglund, Festskrift J. Arvid Hedvall, 1948, 149 . 